This is an electronic reprint of the original article. This reprint may differ from the original in pagination and typographic detail.

Author(s): Lindstedt, Carita; Schroderus, Eero; Lindström, Leena; Mappes, Tapio; Mappes, Johanna

Title: $\quad$ Evolutionary constraints of warning signals : a genetic trade-off between the efficacy of larval and adult warning coloration can maintain variation in signal expression

Year: $\quad 2016$

Version:

Please cite the original version:

Lindstedt, C., Schroderus, E., Lindström, L., Mappes, T., \& Mappes, J. (2016).

Evolutionary constraints of warning signals : a genetic trade-off between the efficacy of larval and adult warning coloration can maintain variation in signal expression. Evolution, 70(11), 2562-2572. https://doi.org/10.1111/evo.13066

All material supplied via JYX is protected by copyright and other intellectual property rights, and duplication or sale of all or part of any of the repository collections is not permitted, except that material may be duplicated by you for your research use or educational purposes in electronic or print form. You must obtain permission for any other use. Electronic or print copies may not be offered, whether for sale or otherwise to anyone who is not an authorised user. 
Evolutionary constraints of warning signals: a genetic trade-off between the efficacy of larval and adult warning coloration can maintain variation in signal expression

Lindstedt, C. ${ }^{1,2}$, Schroderus, E. ${ }^{2}$, Lindström, L. ${ }^{1,2}$, Mappes, T. ${ }^{2}$ and Mappes, J. ${ }^{1,2}$

${ }^{1}$ Centre of Excellence in Biological Interactions Research, ${ }^{2}$ Department of Biological and Environmental Science, P.O. Box 35, 40014 University of Jyväskylä, Finland

Running title: Genetic constraints on signals across life stages

Keywords: life-history, costs of melanism, warning signals, life stage, aposematism, genetic correlations

When the paper will be published, data used in these analyses will be included in

open access databases according to guidelines of the respective scientific journals and the

University of Jyväskylä

Corresponding author:

This article has been accepted for publication and undergone full peer review but has not been through the copyediting, typesetting, pagination and proofreading process, which may lead to differences between this version and the Version of Record. Please cite this article as doi: 10.1111/evo.13066.

This article is protected by copyright. All rights reserved. 


\section{Carita Lindstedt}

Centre of Excellence in Biological interactions,

Department of Biological and Environmental Sciences,

University of Jyväskylä, P.O. Box 35,

FI-40014 University of Jyväskylä, Finland

carita.a.lindstedt@jyu.fi

This article is protected by copyright. All rights reserved. 


\section{Abstract}

To predict evolutionary responses of warning signals under selection, we need to determine the inheritance pattern of the signals, and how they are genetically correlated with other traits contributing to fitness. Furthermore, protective coloration often undergoes remarkable changes within an individual's lifecycle, requiring us to quantify the genetic constraints of adaptive coloration across all the relevant life stages. Based on a 12 generation pedigree with $>11000$ individuals of the wood tiger moth (Arctia plantaginis), we show that high primary defense as a larva (large warning signal) results in weaker defenses as adult (less efficient warning color), due to the negative genetic correlation between the efficacy of larval and adult warning coloration. However, production of effective warning coloration as a larva, did not incur any life-history costs and was positively genetically correlated with reproductive output. These results provide novel insights into the evolutionary constraints on protective coloration in animals, and explain the maintenance of variation in the signal expression despite the strong directional selection by predators. By analyzing the genetic and environmental effects on warning signal and life-history traits in all relevant life stages, we can accurately determine the mechanisms shaping the evolutionary responses of phenotypic traits under different selection environments.

This article is protected by copyright. All rights reserved. 


\section{Introduction}

Signal evolution can be constrained by genetic covariation between signal and other fitness traits (Brodie III 1992, Price \& Burley 1993, Sinervo et al. 2000). Therefore, to understand why variation in maximal signal expression can be maintained despite directional phenotypic selection, it is critical to study the patterns of genetic variation and covariation underlying those traits. In aposematic animals, where individuals communicate their defenses to predators via warning signals, selection by predators is assumed to select for conspicuous (e.g. Gittleman and Harvey 1980, Roper and Redston 1987, Alatalo and Mappes 1996, Gamberale-Stille and Tullberg 1999, Lindström et al. 1999, Lindstedt et al. 2008) and uniform (see e.g. Mallet and Barton 1989, Joron and Mallet 1998, Kapan 2001, Beatty et al. 2004, Rowland et al. 2007) warning signals. Signal conspicuousness ensures that the prey is recognized and learned quickly by a predator that has had previous bad experiences with it, and that the attack stops before the prey is lethally injured. Despite this expectation, there are many aposematic species which show considerable within species variation in signal expression (Ojala et al. 2007, Bezzerides et al. 2007) or even stable local polymorphism (Brakefield 1985, Mallet 1986, Williams 2007, Nokelainen et al. 2013, Rojas and Endler 2013).

New avenues of research have recently opened to explain the maintenance of this variation (Mappes et al. 2005). These go beyond mere predator-prey interaction, taking into account the physiological costs of warning signal production in different environmental conditions (e.g. Grill and Moore 1998, Bezzerides et al. 2007, Ojala et al. 2007, Sandre et al. 2007, Lindstedt et al. 2010a,) as well as multiple selection pressures on signaling and non-signaling functions of coloration (Brakefield 1985, Maan and Cummings 2008, Lindstedt et al. 2009, Friman et al. 2009, Nokelainen et al. 2012, Nokelainen et al. 2013). At the same time, knowledge about the genetic architecture underlying wing patterning in many aposematic Lepidoptera species has helped to identify the genetic changes

This article is protected by copyright. All rights reserved. 
driving variation in warning coloration (e.g. Jiggins et al. 2012, Supple et al. 2013, Welch and Jiggins 2014). However, to be able to predict evolutionary response of warning signal traits to selection, we also need information about the inheritance of warning signal traits and how they correlate genetically with other morphological and life-history traits.

Negative genetic correlations among color and life-history traits can maintain additive genetic variation in fitness: for example, in Poecilia reticulata guppy males, negative genetic correlation between color traits and ejaculate size maintains continuous variation in sexual ornamentation (Evans 2010). In some cases, like in side blotch lizards (Uta stansburiana) (Sinervo et al. 2000, Svensson et al. 2001) and the garter snakes (Thamnopsis ordinoides) (Brodie III 1989), genetic correlations among life-history, color and behavioral traits have led to the maintenance of color polymorphism, when coupled with correlated selection. Among aposematic species, phenotypic trade-offs have been shown between life-history traits and signal expression (Grill and Moore 1998, Ojala et al. 2007, Friman et al. 2009, Nokelainen et al. 2013), but much less effort has been put into understanding genetic correlations between warning signal and fitness traits (but see Holloway et al. 1995, Lindstedt et al. 2009 for inheritance of signal traits).

Genetic correlations can also be formed among different pattern elements of adaptive coloration. This can result tight, independently evolving units that reflect either common developmental origin (e.g. eyespots in the wings of Bicyclus anyana butterfly) or functional coadaptation (e.g. wing melanin patterns and thermoregulation in Pieris occidentalis butterflies) or both (Kingsolver and Wiernasz 1991, Monteiro et al. 1994, Monteiro et al. 1997). Due to developmental organization and strong genetic correlations, changes in the selection pressures on one of these correlated traits have been shown to cause indirect responses in other correlated traits

This article is protected by copyright. All rights reserved. 
constraining evolutionary change within these 'color pattern units' within one life stage (i.e. adult butterfly) (Kingsolver and Wiernasz 1991, Brakefield and French 1999).

However, many species undergo more than one life-stage during their development, and the fitness of an individual as an adult is always dependent on the fitness of its earlier life stages (Grill and Moore 1998, Lindstedt et al. 2010a, Nokelainen et al. 2013). Furthermore, it is not known how larval and adult defensive coloration covary genetically. Many aposematic insects and vertebrates express bright warning coloration at the between both larval and adult life stages (Marples et al. 1994, Gamberale-Stille and Tullberg 1999, Beltran et al. 2007, Lindstedt et al. 2008, Lindstedt et al. 2011, Nokelainen et al. 2012, Stynoski et al. 2014, Stynoski et al. 2014, Umbers and Mappes 2015). If color elements of larval and adult warning coloration are genetically correlated, variation expressed in adult coloration could be maintained not only via direct responses to selection on color traits in adults but also through indirect responses of selection on larval coloration and vice versa. Depending on the direction of the genetic correlations between warning signal traits across life stages, this could either enhance or constrain the evolutionary responses to phenotypic selection.

The aposematic wood tiger moth (Arctia plantaginis, formerly Parasemia plantaginis Rönkä et al. 2016) is a model system to study various aspects of warning coloration (e.g. Lindstedt et al. 2009, Nokelainen et al. 2012, Hegna et al. 2013, Nokelainen et al. 2014, Galarza et al. 2015). Both larvae and adults of this species display locally and geographically diverse warning signals. Adult male hind wing coloration is sex-linked, resulting in a polymorphic white or yellow/orange wing pigmentation (Nokelainen et al. 2013, Galarza et al. in prep.) and the warning coloration of larvae (Lindstedt et al. 2009) and females (Lindstedt et al. 2010a, Lindstedt et al. 2011) varies continuously (Fig. 1). Based on previous studies, the size of the orange patch on the otherwise black and hairy body of the larvae is known to be highly heritable (Lindstedt et al. 2009, see below). The black

This article is protected by copyright. All rights reserved. 
coloration is based on eumelanin pigments and the orange hairs of the larvae contain both eumelanin pigments and traces of flavonoids (Lindstedt et al. 2010b). The bright orange to red color seen in the hindwings of adult females is mainly composed of erythropterins and black patterns are eumelanin (Burdfield-Steel et al. unpublished).

Variation in coloration in wood tiger moths is partly explained by varying selective environments. Predator-prey assays in the laboratory suggest directional selection for conspicuous warning signals of larvae, as birds hesitate longer before attacking larvae with large orange patch in comparison to larvae with small orange patch (i.e. more melanic ones) (Lindstedt et al. 2008) (Fig. 1). In contrast, the more melanic larvae have better defense against pathogenic bacteria (Friman et al. 2009), and they are more efficient in thermoregulation (Lindstedt et al. 2009) than larvae with larger orange warning signals. Selection by predators favors adult females with a higher intensity of red over those with more yellow/orange coloration in their hindwings (Lindstedt et al. 2011), (Fig 1.). Adult females grown on larval diets with a high content of defense chemicals have less efficient warning coloration (i.e. more orange than red) in their wings, and they produce fewer offspring due to increased detoxification costs (Lindstedt et al. 2010a). Therefore, the conditions experienced as a larva can induce phenotypic variation in the signal efficacy and life-history traits of adults. However, to be able to make predictions about the rate and direction of evolutionary responses of signal traits in all the relevant life stages, we need to reach further and study the potential genetic and phenotypic trade-offs within and between the life stages in signal and life-history traits. The continuous genetic variation in coloration of both larvae and females of $A$. plantaginis offers a unique possibility to test fitness correlates over multiple life-history stages.

In order to identify potential sources of variation in signal expression, we examined the genetic and maternal covariance between (a) the signal traits of larvae (size of the orange patch) and

This article is protected by copyright. All rights reserved. 
adult females (intensity of red coloration), (b) the signal and key life-history traits and (c) the signal and reproductive traits. We used a linear REML-animal model to analyze the pedigrees of 12 generations, that included the information on 11742 individual's signal types as a larva and adults and both life-history traits (development time, pupa mass) and reproductive traits (number of eggs and number of hatched offspring female produced). We assumed that phenotypic and genetic variation expressed both in larval (Ojala et al. 2007, Lindstedt et al. 2009) and adult coloration (Lindstedt et al. 2010) could be maintained if there is negative genetic correlation between the expression of efficient warning signals and life-history traits and/or if there is negative genetic correlation between the signal efficiency of larval and adult life stages.

\section{Methods}

\section{Study organism}

The larvae of the Arctiid moth Arctia plantaginis (Arctiidae) are polyphagous and feed on numerous herbaceous and arborescent plant species (Ojala et al. 2005). The coloration of both larvae and adults (Fig. 1) varies, which is typical for Arctiid moths (Fisher and Ford 1947, Brakefield and Liebert 1985, Fields and McNeil 1988). Arctiid moths are also generally known to sequester plant's defense chemicals and use them for their own defense (Weller et al. 1999, Lindstedt et al. 2010a, Reudler Talsma et al. 2015). A. plantaginis moths can also synthetize pyrazines de novo, which protects them effectively against avian predators (Burdfield-Steel et al. in prep)

The larvae are hairy and have moderately conspicuous coloration comprised of an orange patch on an otherwise black body. The size of this orange patch varies continuously both

This article is protected by copyright. All rights reserved. 
phenotypically and genetically (Ojala et al. 2007, Lindstedt et al. 2009). Larvae produce the orange patch by depositing eumelanin and traces of diet derived flavonoids in their hairs (Lindstedt et al. 2010b). The black color is based purely on higher concentrations of eumelanin (Lindstedt et al. 2010b). The larvae have 5-7 instars, the first two of which are cryptically colored; orange-black coloration develops at the third instar (Ojala et al. 2007). Arctiid moths are capital breeders, i.e. the adults do not feed, making the larval diet critical for the fitness of adults. The adults are diurnal and also conspicuously colored: males are either black and white or black and yellow and females are usually black and white with red-to-orange body and hind wings (Fig. 1). The coloration of the body and hind wings of females varies continuously from orange/yellow to red (Lindstedt et al. 2010a, Lindstedt et al. 2011) and pigmentation in females has recently been shown to be based mainly on erythropterins (Burdfield-Steel et al. unpublished).

In Finland, this species usually has one generation per year and typically overwinters as 3rd 4th instar larva. In laboratory conditions A. plantaginis can produce two generations per year and the second generation overwinters.

\section{Pedigrees}

The pedigrees of $A$. plantaginis include 12 generations from the laboratory stock that was established in 2003 from wild caught copulated females collected from different localities in Central Finland $(\mathrm{N}=15)$ and Åland $(\mathrm{N}=5)$ and supplemented annually with wild individuals caught from the nearby regions of Central Finland. During the following two generations, 30 - 50 breeding adults were reared in each generation and the effective population size was kept as large as possible to maintain genetic variation. After two generations, the lab stock was divided to upward and downward selection lines for divergent phenotypes of larval color (i.e. the large and small orange

This article is protected by copyright. All rights reserved. 
signals) by applying a truncated family selection protocol to the stock (Lynch and Walsh 1998). We selected both the individuals with large (number of segments with orange hairs in larva is 6 or more) and small signals (number of segments with orange hairs in larva is 4 or less) within the family. After selection, we crossed the individuals exceeding the threshold value of selected signal sizes within the selection lines in the following generations. The pedigrees used in the analyses include individuals from both before and after the establishment of selection lines (starting from the first lab generation). It is possible that artificial selection for the larval signal size could affect the structure of genetic correlations across life-stages. Nevertheless, animal model takes into account the selection and results refer to the genetic variation in the base population. In addition, similar genetic correlations can be found from the unselected $A$. plantaginis populations (Gordon et al. unpublished).

The lab stock was reared in laboratory conditions $(25 \stackrel{\circ}{\circ})$ in a greenhouse at the University of Jyväskylä in Central Finland. Adults were mated randomly within lines by putting one male and one female into separate plastic box. Females laid eggs in the box and, 14 days after hatching, we randomly chose up to 60 still cryptically colored larvae per family and divided them into separate plastic boxes for further rearing, 20 larvae per box. To get individual information, 10 - 40 larvae per family, depending on the generation, were moved to petri dishes to be reared individually when they reached their second last or last instar. During the rearing, larvae were fed with a mixed diet of lettuce and dandelion (Taraxacum sp.) leaves. For the hibernating generation, willow leaves (Salix sp.) were offered as an additional food before the wintering period.

We have collected the following information from all of the individuals ( $n=11742$ ): development time (days), pupal weight (mg), the number of eggs produced, the number of brood offspring, warning signal size in the last instar, and coloration as an adult. Larval coloration was

This article is protected by copyright. All rights reserved. 
measured from the last instar as the number of segments including orange hairs. Since larvae always have 13 body segments, this measure estimates the proportional size of the orange patch on the larval body (Lindstedt et al. 2009). The hindwing color of the females was categorized by human eye on a scale from 1 to 6 , 1-being the most yellow, 3-4 orange and 5-6 the most red (Fig 1 ). The match between "By-eye" categorization and reflectance was confirmed with spectrophotometer measurements (Lindstedt et al. 2010a) and birds' ability to discriminate colors was confirmed by an analysis with the avian vision model (Lindstedt et al. 2011).

\section{Statistical Analyses}

Development time was In-transformed to achieve a distribution closer to normal. The statistical relevance of fixed effects was initially studied with univariate general linear models (GLM) in SPSS (version 20.0), excluding all random effects except for the residual. The only fixed effect included in the subsequent analysis for all the traits was generation of the selection lines. In addition, sex was included for the analysis of larval signal size and development time. Analysis for reproductive output and adult coloration included only females. The variance components were estimated by using REML-animal model implemented in ASReml 3.0 -software (VSN international Ltc, Hemel Hempstead, UK). In complex pedigrees this method is powerful for estimating additive genetic variance and genetic correlations. It utilizes all the information from the pedigree, takes selection into account and, under the infinitesimal model, gives unbiased estimates of the (co)variance components in the base population (e.g. Henderson 1976, Lynch and Walsh 1998).

To analyse the quantitative genetic parameters, a standard linear animal model was used:

This article is protected by copyright. All rights reserved. 
$y=X b+Z_{1} a+Z_{2} c+e$

In which, $\mathbf{y}$ is the vector of phenotypic records; $\mathbf{b}$ is the vector of fixed effects; $\mathbf{a}$ is the vector of direct additive genetic effects; $\mathbf{c}$ is the vector of common-family effect; and $\mathbf{e}$ is the vector of residuals including dominance variance. Common-family effect in the present analysis represents all genetic and non-genetic maternal effects as well as strictly environmental effects common to the brood. Fixed and random effects are fitted to individual records by incidence matrices $\mathbf{X}, \mathbf{Z}_{\mathbf{1}}$ and $\mathbf{Z}_{\mathbf{2}}$. The statistical significance of variance components was assessed with a Log Likelihood ratio test by dropping out alternately each random effect and comparing the Log Likelihood of the restricted model to full model. Heritabilities and common-family effects are reported from the univariate models.

Genetic correlations were estimated with a six trait model fitting all the traits simultaneously. The significance of the covariances were assessed by performing a Log Likelihood ratio test between a full model and model in which covariance in question was constrained to zero.

\section{Results}

\section{Genetic correlation of warning signal expression across lifestages}

Both larval orange warning signal size and the intensity of red in female warning coloration were significantly heritable (Table 1). Interestingly, there was a significant negative genetic correlation between the efficiency of warning coloration in larvae and adult females ( $r g=-0.20, \pm 0.06 \mathrm{SE}$ ), implying that larvae with large orange warning signals develop less red (i.e. more orange) wing coloration as adult females (Fig 1, full statistics and model comparisons for all the genetic and phenotypic correlations reported in Table 2).

This article is protected by copyright. All rights reserved. 


\section{Warning signal efficiency and life history traits}

All the life-history traits measured were heritable (Table 1). Larval orange signal size and the reproductive output of females ( $r g=0.48 \pm 0.20$ for eggs, $r g=0.29 \pm 0.12$ for offspring number) were significantly genetically positively correlated (Table 2). In general, individuals that took longer to develop (irrespective of the larval signal size) produced more eggs due to positive genetic correlation $(\mathrm{rg}=0.60, \pm 0.29 \mathrm{SE}$, Table 2). However, development time and pupa mass did not correlate significantly genetically with the size of the orange signal in larvae (Table 2). There were no significant genetic correlations between the warning signal efficacy of adult females and the lifehistory traits measured (Table 2).

\section{Discussion}

Increasing our knowledge of the multiple selection pressures acting on warning signal expression has helped us to determine how high diversity in warning signal expression is maintained at the phenotypic level (Grill and Moore 1998, Maan and Cummings 2008, Friman et al. 2009, Lindstedt et al. 2009, Nokelainen et al. 2012, Valkonen et al. 2012, Nokelainen et al. 2013, Mappes et al. 2014, Nokelainen et al. 2014, Gordon et al. 2015). However, to predict the evolutionary responses of warning signal traits from one generation to the next, we need information on the inheritance of these traits and how they are genetically correlated with other fitness traits, as these genetic correlations can either enhance or constrain the rate and direction of short-term evolutionary changes. Here we show that the heritability of the efficient warning signal (large orange patch as a larva and red color as an adult female) in A. plantaginis is high. This combined with the absence of

This article is protected by copyright. All rights reserved. 
genetic life-history constraints for the maximal signal expression (i.e. there is a positive genetic correlation between the signal efficacy of larvae and reproductive output), should allow for rapid response to the directional selection imposed by predators (Lindstedt et al. 2008, 2011) and select for a large warning signal as a larvae and red coloration as an adult. However, the negative genetic correlation between the efficient adult female warning coloration and efficient larval warning coloration could preserve additive genetic variation in signal expression, offering an interesting and novel explanation for why the continuous genetic variation in warning color is maintained among larvae and females in A. plantaginis populations.

The magnitude of the trade-off between larval and female warning signal efficiency can be strongly dependent on the spatial and temporal variation in the direction and strength of selection. Previous studies have shown that warning coloration of larvae and adults of $A$. plantaginis are under multiple selection pressures, as predation favors an increase in size and conspicuousness of brightly colored pattern elements (Lindstedt et al. 2008, Lindstedt et al. 2011, Nokelainen et al. 2012) while thermoregulation (Lindstedt et al. 2009, Hegna et al. 2013) and defense against pathogens (Friman et al. 2009; Zhang et al. 2012) favors more melanic coloration with less conspicuous, and smaller sized, bright patterns. In addition, the strength and direction of selection on the warning signal traits can vary both spatially (Lindstedt et al. 2011, Nokelainen et al. 2014, Gordon et al. 2015) and seasonally (Mappes et al. 2014) in nature. Together these different selection pressures could form a geographic mosaic of selection favoring different trait combinations across different life stages and maintain additive variation in signal traits (Gordon et al. 2015).

The specific developmental or molecular mechanisms behind the genetic correlations among color and life-history traits in A. plantaginis are at present unknown. However, pleiotropic effects of genes influencing the regulation of hormones on color, physiology and life-history traits (Nijhout and

This article is protected by copyright. All rights reserved. 
Emlen 1998, Svensson et al. 2001, Flatt et al. 2005, Schroderus et al. 2010) could potentially play a key role. For example, juvenile hormone $(\mathrm{JH})$ has been shown to have a wide impact on the phenotype of many insect species and it has suggested to be one of the major determinants of pleiotropy, life history correlations and trade-offs throughout the life cycle of an insect (Dingle and Winchell 1997, Gade et al. 1997, Flatt et al. 2005). It has also shown to have effects on insect coloration at both larval and adult life stages, and induce changes in the expression of regulatory genes that code pigment synthesis in life stage -specific switches in adaptive color patterns in Papilio xuthus -butterfly caterpillars (Futahashi and Fujiwara 2005, 2008). Considering its multiple phenotypic effects on life-history traits and regulation of pigmentation in insects across life stages, juvenile hormones may offer one potential developmental mechanism for the genetic correlations we observed in A. plantaginis moths. However, this hypothesis needs to be experimentally tested.

In contrast to many studies on the costs of bright color signals in vertebrates (e.g. Endler 1980, Hill and Montgomerie 1994, Grether et al. 2001, Hill et al. 2002, Boratynski et al. 2014), our study, along with the others (Saffranek and Riddiford 1975, Windig 1999, Talloen et al. 2004, Stoehr 2006, Ojala et al. 2007, Ma et al. 2008), further emphasizes that melanin based black patterns can be more costly to produce for herbivorous insect species than bright pigment based colors. In our data, A. plantaginis individuals that were less melanic as a larva, had a higher reproductive output as an adult due to positive genetic correlation. Female coloration did not correlate significantly with reproductive output, measured here as offspring production following a single mating. Animals synthesize melanins and pterines de novo from the amino acid tyrosine (Sugumaran 2002). As these resources are needed for other important physiological functions, such as immunological processes, the production of melanin pigments is likely to compete with other physiological traits (Stoehr 2006, Lee et al. 2008). Furthermore, amino acids are often scarce in plants and therefore the limiting nutrient for herbivores (Mattson 1980, Morehouse and Rutowski 2010). Protein scarcity in diet has

This article is protected by copyright. All rights reserved. 
also been shown to induce phenotypic variation in immunological traits and melanin based coloration in Spodoptera littoralis moths (Lee et al. 2008). In A. plantaginis, both larval coloration (mainly based on different concentrations of eumelanin) and female coloration (black is eumelanin and red-orange is erythropterines) are dependent on the amino acid content of the diet. Therefore, it is possible that under limited resources, the reproductive effort of more melanic individuals, with more costly pigmentation, has been constrained: influencing the structure of genetic covariance among these traits.

As both larval signal size and development time are heritable and phenotypically correlated, it is tempting to speculate that the two extremes of larval signal types may represent two different strategies that could be regulated via maternal effects (Schneiderman and Horwitsz 1958, Beach 1978, Mousseau and Dingle 1991). A. plantaginis hibernates as larvae and they only have one generation during the growing season in the Northern Europe. As melanic larvae are probably better protected against the challenges of the wintering period (better adapted to cold (Lindstedt et al. 2009) and more resistant to disease (Friman et al. 2009)) or colder growing season (Lindstedt et al. 2009), the shorter development time of more melanic larvae, and better warning signal efficacy as a female could ensure the completion of the generation during one growing season. On the other hand, in southern populations with a warmer and longer growing season, less melanic larvae with longer development times but with more efficient warning signals and higher reproductive output could be favored (see also e.g. Hazel 2002). As the larval stage is much longer (approx. 11 months) compared to the adult stage (approx. 2-3 weeks), selection for the larval coloration might even be stronger than for the adult female coloration (see also Lindstedt et al. 2011). If pigment synthesis at both the larval stage and metamorphosis are regulated by the same genes, the production of red females may just be a by-product of stronger selection for the melanism in larvae in colder climates and habitats or under high risk of pathogens.

This article is protected by copyright. All rights reserved. 
Several studies show that the conditions experienced at younger life stages, can have effects on warning signal efficacy in adults (e.g. Grill and Moore 1998, Talloen et al. 2004, Davis et al. 2005, Lindstedt et al. 2010a, Blount et al. 2012). However, our study brings a novel and interesting perspective for life-history studies by showing that negative genetic correlations between larval and adult life stages may play a role in the evolution of warning coloration, maintaining additive genetic variation in color expression. Further information on the developmental and molecular mechanisms behind the color pigment production between different life stages is needed to understand whether our finding is part of a more general phenomenon, that could have broad significance on how we understand the maintenance of diversity in intra- and interspecific signaling and evolution of protective coloration. More broadly, our results emphasize the importance of taking into account the whole life-history of an animal, and the various selection pressures over the different developmental stages, when investigating signal evolution.

\section{Acknowledgements}

This study was funded by the Academy of Finland via the Centre of Excellence in Biological Interactions Research (J. Mappes) and the projects no 132190, 268670 (T. Mappes) and 257581 (C. Lindstedt) and Ella and Georg Ehrnrooth foundation (C. Lindstedt). We are also grateful for Katja Ojala and all the research assistants helping with the maintenance of lab population. Tarmo Ketola and Emily Burdfield-Steel kindly commented the earlier versions of the manuscript.

\section{Literature cited}

Alatalo, R. and J. Mappes. 1996. Tracking the evolution of warning signals. Nature 382: 708-710.

This article is protected by copyright. All rights reserved. 
Beach, R. 1978. The required day number and timely induction of diapause in geographic strains of the mosquito Aedes atropalpus. J. Insect. Physiol. 24:449-55.

Beatty, C. D., K. Beirinckx, and T. N. Sherratt. 2004. The evolution of Müllerian mimicry in multispecies communities. Nature 431:63-67.

Beltran, M., C. D. Jiggins, A. V. Z. Brower, E. Bermingham, and J. Mallet. 2007. Do pollen feeding, pupal-mating and larval gregariousness have a single origin in Heliconius butterflies? Inferences from multilocus DNA sequence data. Biol. J. Linn. Soc. Lond. 92:221-239.

Bezzerides, A., K. MacGraw, R. Parker, and J. Husseini. 2007. Elytra colour as a signal of chemical defence in the Asian ladybird beetle Harmonia axyridis. Behav. Ecol. Sociobiol. 61:1401-1408.

Blount, J.D., H. M. Rowland, F. P. Drijfhout, J. A. Endler, R. Inger, J. J. Sloggett, G. D. D Hurst, D. J. Hodgson, and M. P. Speed. 2012. How the ladybird got its spots: effects of resource limitation on the honesty of aposematic signals. Func. Ecol. 26:334-342.

Boratynski Z, P. Lehmann, T. Mappes, T. A. Mousseau and A. P. Møller 2014. Increased radiation from Chernobyl decreases the expression of red colouration in natural populations of bank voles (Myodes glareolus). Scientific Reports 4:7141

Brakefield, P. M., and T. G. Liebert. 1985. Studies of colour polymorphism in some marginal populations of the aposematic jersey tiger moth Callimorpha quadripunctaria. Biol. J. Linn. Soc. Lond. 26:225-241.

Brakefield, P.M. 1985. Polymorphic Müllerian mimicry and interactions with thermal melanism in ladybirds and a soldier beetle: a hypothesis. Biol. J. Linn. Soc. Lond. 26:243-267.

Brakefield, P., and V. French. 1999. Butterfly wings: the evolution of development of colour patterns. BioEssays 21:391-401. 
Brodie III, E. D. 1992. Correlational selection for color pattern and antipredator behavior in the garter snake Thamnophis ordinoides. Evolution 46:1284-1298.

Damman, H. 1987. Leaf quality and enemy avoidance by the larvae of a pyralid moth. Ecology 68:8897.

Davis, A. K., B. D. Farrey, and S. Altizer. 2005. Variation in thermally induced melanism in monarch butterflies (Lepidoptera: Nymphalidae) from three North American populations. J. Therm. Biol. $30: 410-421$

Dingle, H., and R. Winchell. 1997. Juvenile hormones as a mediator of plasticity in insect life histories. Arch. Insect. Biochem. Physiol. 35:359-373.

Endler, J.A. 1980. Natural selection on colour patterns in Poecilia reticulata. Evolution 34:76-91.

Evans, J. P. 2010. Quantitative genetic evidence that males trade attractiveness for ejaculate quality in guppies. Proc. R. Soc. B. 277:3195-3201.

Fields, P. G., and J. N. McNeil. 1988. The importance of seasonal variation in hair colouration for thermoregulation of Ctenucha virginica larvae (Lepidoptera: Arctiidae). Physiol. Entomol. 13:165175.

Fisher, R. A., and E. B. Ford. 1947. The spread of a gene in natural conditions in a colony of the moth Panaxia dominula L. Heredity 1:143-174.

Flatt, T, M. P. Tu, and M. Tatar. 2005. Hormonal pleiotropy and the juvenile hormone regulation of Drosophila development and life history. BioEssays 27:999-1010.

Friman, V., C. Lindstedt, T. Hiltunen, J. Laakso, and J. Mappes. 2009. Predation on multiple trophic levels shapes the evolution of pathogen virulence. PLoS ONE 4: e6761. 
Futahashi, R., and H. Fujiwara. 2005. Melanin-synthesis enzymes coregulate stage-specific larval cuticular markings in the swallowtail butterfly, Papilio xuthus. Dev. Genes. Evol. 215:519-529.

Futahashi, R., and H. Fujiwara. 2008. Juvenile hormone regulates butterfly larval pattern switches. Science 319:1061.

Gade, G., K. H. Hoffman, and J. H. Spring. 1997. Hormonal regulation in insects: facts, gaps and future directions. Physiol. Rev. 77:963-1032.

Galarza, J.A., O. Nokelainen, R. H. Hegna, R. Ashrafi, and J. Mappes. 2014. Temporal relationship between genetic and warning signal variation in the aposematic wood tiger moth (Parasemia plantaginis). Mol. Ecol. 23:4939-4957.

Gamberale-Stille, G., and B. Tullberg. 1999. Experienced chicks show biased avoidance of stronger signals: an experiment with natural colour variation in live aposematic prey. Evol. Ecol. 13:579-589.

Gittleman, J. L., and P. H. Harvey. 1980. Why are distasteful prey not cryptic? Nature 286:149-150.

Gordon, S. P., H. Kokko, B. Rojas, O. Nokelainen, and J. Mappes. 2015. Colour polymorphism torn apart by opposing positive frequency-dependent selection, yet maintained in space. J. Anim. Ecol. 84:1555-1564.

Grether, G., J. Hudon, and J. A. Endler. 2001. Carotenoid scarcity, synthetic pteridine pigments and the evolution of sexual colouration in guppies (Poecilia reticulate). Proc Biol Sci. 268:1245-1253.

Grill, C. P., and A. J. Moore. 1998. Effects of a larval antipredator response and larval diet on adult phenotype in an aposematic ladybird beetle. Oecologia 114:274-282.

Hazel, W. N. 2002. The environmental and genetic control of seasonal polyphenism in larval colour and its adaptive significance in a swallowtail butterfly. Evolution 56:342-348. 
Hegna, R. H., O. Nokelainen, J. Hegna, and J. Mappes. 2013. To quiver or to shiver: increased melanization benefits thermoregulation, but reduces warning signal efficacy in the wood tiger moth. Proc Biol Sci. 280: 2012-2812.

Hegna, R. H., and J. Mappes. 2014. Influences of geographic differentiation in the forewing warning signal of the wood tiger moth in Alaska. Evol. Ecol 28: 1003-1017.

Hegna, R. H., J. A. Galarza, and J. Mappes. 2015. Global phylogeography and geographical variation in warning coloration of the wood tiger moth (Parasemia plantaginis). J. Biogeogr. 42:1469-1481.

Henderson, C. R. 1976. Simple method for computing inverse of a numerator relationship matrix used in prediction of breeding values. Biometrics 32:69-83.

Hill, G.E., and R. Montgomerie. 1994. Plumage colour signals nutritional condition in the house finch. Proc. Biol. Sci. 258:47-52.

Hill, G. E., C. Y. Inouye, and R. Montgomerie. 2002. Dietary carotenoids predict plumage coloration in wild house finches. Proc. Biol. Sci. 269:1119-1124.

Holloway, G. J., P. M. Brakefield, P. W. De Jong, M. M. Ottenheim, H. De Vos, F. Kesbeke, and L. Peynenburg. 1995. A quantitative genetic analysis of an aposematic colour pattern and its ecological implications. Phil. Trans. R. Soc. Lond. 348:373-379.

Joron, M., and J. L. B. Mallet. 1998. Diversity in mimicry: paradox or paradigm? Trends Ecol. Evol. $13: 461-466$.

Kapan, D. D. 2001. Three-butterfly system provides a field test of müllerian mimicry. Nature 409:338-340.

Kingsolver, J. G., and D. C. Wiernasz. 1991. Development, function, and the quantitative genetics of wing melanin pattern in Pieris butterflies. Evolution 45:1480-1492.

This article is protected by copyright. All rights reserved. 
Lee, K. P., S. J. Simpson, and K. Wilson. 2008. Dietary protein-quality influences melanization and immune function in an insect. Func. Ecol 22:1052-1061.

Lindstedt, C., H. Eager, E. Ihalainen, A. Kahilainen, M. Stevens, and J. Mappes. 2011. Direction and strength of selection by predators for the hindwing color of the aposematic wood tiger moth. Behav. Ecol. 22:580-587.

Lindstedt, C., L. Lindström, and J. Mappes. 2008. Hairiness and warning colours as components of antipredator defence: additive or interactive benefits? Anim. Behav. 75:1703-1713.

Lindstedt, C., L. Lindström, and J. Mappes. 2009. Thermoregulation constrains effective warning signal expression. Evolution 63:469-478.

Lindstedt, C., J. H. Reudler Talsma, E. Ihalainen, L. Lindström, and J. Mappes. 2010a. Diet quality affects coloration indirectly: excretion costs in a generalist herbivore. Evolution 64:68-78.

Lindstedt, C., N. Morehouse, H.Pakkanen, J. Casas, J. Christides, K. Kemppainen, L. Lindström, and J. Mappes. 2010b. Pigment composition of a variable warning signal of Parasemia plantaginis larvae (Arctiidae). Func. Ecol. 24:759-766.

Lindström, L., R. V. Alatalo, J. Mappes, M. Riipi, and L. Vertainen. 1999. Can aposematic signals evolve by gradual change? Nature 397:249-251.

Lynch, M., and B. Walsh. 1998. Genetics and analysis of quantitative traits. Sinauer associates, Inc., Massachusetts. pp. 745-800.

Ma, W., L. Chen, M. Wang, and X. Chunli. 2008. Trade-offs between melanisation and life-history traits in Helicoverpa armigera. Ecol. Entomol. 33:37-44.

Maan, M. E., and M. E. Cummings. 2008. Female preferences for aposematic signal components in a polymorphic poison frog. Evolution 62:2334-2345.

This article is protected by copyright. All rights reserved. 
Mallet, J. 1986. Hybrid zones of Heliconius butterflies in Panama and the stability and movement of warning colour clines. Heredity 56:191.

Mallet, J., and N. H. Barton. 1989. Strong natural selection in a warning-colour hybrid zone. Evolution 43: 421-431.

Mappes, J., H. Kokko, K. Ojala, and L. Lindström. 2014. Seasonal changes in predator community switch the direction of selection for anti-predatory defences. Nat. Commun. 5: 5016.

Mappes, J., N. Marples, and J. A. Endler. 2005. The complex business of survival by aposematism. Trends Ecol. Evol. 20:598-603.

Marples, N. M., W. VanVeelen, and P. M. Brakefield. 1994. The relative importance of colour, taste and smell in the protection of an aposematic insect Coccinella septempunctata. Anim. Behav. 48:967974.

Mattson, W. 1980. Herbivory in relation to plant nitrogen content. Ann. Rev. Ecol. Syst. 11: 119-161.

Monteiro, A. F., P. M. Brakefield, and V. French. 1994. The evolutionary genetics and developmental basis of wing pattern variation in the butterfly Bicyclus anynana. Evolution 48:1147-1157.

Monteiro, A. F., P. M. Brakefield, and V. French. 1997. Butterfly eyespots: The genetics and development of the color rings. Evolution 51:1207-1216.

Morehouse, N.I., and R. L. Rutowski. 2010. Developmental responses to variable diet composition in the cabbage white butterfly, Pieris rapae: the role of nitrogen, carbohydrates and genotype. Oikos 119:636-645.

Mousseau, T.A., and H. Dingle. 1991. Maternal effects in insect life histories. 1991. Maternal effects in insect life histories. Annu. Rev. Entomol 36:511-34.

This article is protected by copyright. All rights reserved. 
Nijhout, H. F., and D. J. Emlen. 1998. Competition among body parts in the development and evolution of insect morphology. Proc. Nat. Acad..Sci. 95:3685-3689.

Nokelainen, O., R. H. Hegna, J. H. Reudler Talsma, C. Lindstedt, and J. Mappes. 2012. Trade-off between warning signal efficacy and mating success in the wood tiger moth. Proc. Biol. Sci. 279:257265.

Nokelainen, O., C. Lindstedt, and J. Mappes. 2013. Environment-mediated morph-linked immune and life-history responses in the aposematic wood tiger moth. J. Anim. Ecol. 3:653-662.

Nokelainen, O., J. Valkonen, C. Lindstedt, and J. Mappes. 2014. Changes in predator community structure shifts the efficacy of two warning signals in Arctiid moths. J. Anim- Ecol. 83:598-605.

Ojala, K., R. Julkunen-Tiitto, L. Lindström, and J. Mappes. 2005. Diet affects the immune defence and life-history traits of an Arctiid moth Parasemia plantaginis. Evol. Ecol. Res. 7:1153-1170.

Ojala, K., L. Lindström, and J. Mappes. 2007. Life history constraints and warning signal expression in arctiid moth. Func. Ecol. 21:1162-1167.

Price, D. K., and N. T. Burley, 1993. Constraints on the evolution of attractive traits: genetic (co)variance of zebra finch bill colour. Heredity 71:405-412.

Reudler-Talsma, J. H., C. Lindstedt, H. Pakkanen, I. Lehtinen, and J. Mappes. 2015. Costs and benefits of plant allelochemicals in herbivore diet in a multienemy world. Oecologia 179:1147-1158.

Rojas, B., and J. A. Endler. 2013. Sexual dimorphism and intra-populational colour pattern variation in the aposematic frog Dendrobates tinctorius. Evol. Ecol. 27:739-753.

Roper, T.J., and S. Redston. 1987. Conspicuousness of distasteful prey affects the strength and durability of one-trial avoidance learning. Anim. Behav. 35:739-747.

This article is protected by copyright. All rights reserved. 
Rowland, H. M., E. Ihalainen, L. Lindström, J. Mappes, and M. P. Speed. 2007. Co-mimics have a mutualistic relationship despite unequal defence levels. Nature 448:64-66.

Rönkä, K., J. Mappes, L. Kaila, and N. Wahlberg. 2016. Putting Parasemia in its phylogenetic place: a molecular analysis of the subtribe Arctiina (Lepidoptera). Syst. entomol.. DOI: 10.1111/syen.12194.

Saffranek, L.. and L. M. Riddiford. 1975. The biology of the black larval mutant of the tobacco hornworm, Manduca sexta. J. Insect. Physiol. 21:1931-1938.

Sandre, S., T. Tammaru, T. Esperk, R. Julkunen-Tiitto,and J. Mappes. 2007. Carotenoid-based colour polyphenism in a moth species: search for fitness correlates. Entomol. Exp. App. 124:269-277.

Schneiderman, H.A., and J. Horwitz. 1958. The induction and termination of facultative diapause in the chalcid wasps Mormoniella vitipennis (Walker) and Trineptis klugii (Ratzeburg). J. Exp. Biol. $35: 520-51$.

Schroderus, E., I. Jokinen, M. Koivula, E. Koskela, T. Mappes, S. C. Mills,T. A. Oksanen, and T. Poikonen. 2010. Intra- and intersexual trade-offs between testosterone and immune system: implications for sexual and sexually antagonistic selection. Am. Nat. 176: E90-97.

Sinervo, B. , E. Svensson, and T. Comendant. 2000. Density cycles and an offspring quantity and quality game driven by natural selection. Nature 406:985-988.

Stoehr, A. M. 2006. Costly melanin ornaments: the importance of taxon? Func. Ecol. 20:276-281.

Stynoski, J. L., G. Shelton, and P. Stynoski. 2014. Maternally derived chemical defences are an effective deterrent against some predators of poison frog tadpoles (Oophaga pumilio). Biol. Lett. 10:1-4.

This article is protected by copyright. All rights reserved. 
Stynoski, J. L., Y. Torres-Mendoza, M. Sasa-Marin, and R. A. Saporito. 2014. Evidence of maternal provisioning of alkaloid-based chemical defences in the strawberry poison frog Oophaga pumilio. Ecology 95:587-593.

Sugumaran, M. 2002. Comparative biochemistry of eumelanogenesis and the protective roles of phenoloxidase and melanin in insects. Pigment Cell Research 15:2-9.

Supple, M. A., H. M. Hines, K. K. Dasmahapatra, J. J. Lewis , D, M. Nielsen , C. Lavoie, D. A. Ray, C. Salazar, W. O. McMillan, and B. A. Counterman. 2013. Genomic architecture of adaptive colour pattern divergence and convergence in Heliconius butterflies. Genome Res. 1-39.

Svensson, E., B. Sinervo, and T. Comendant. 2001. Density-dependent competition and selection on immune function in genetic lizard morphs. Proc. Natl. Acad. Sci. 98:12561-12565.

Svensson, E., B. Sinervo, and T. Comendant. 2002. Mechanistic and experimental analysis of condition and reproduction in a polymorphic lizard. J. Evol. Biol. 15:1034-1047.

Talloen, W., H. Van Dyck, and L. Lens. 2004. The cost of melanisation: butterfly wing colouration under environmental stress. Evolution 56:360-366.

Teder, T. and T. Tammaru. 2001. Large larvae of a flush-feeding moth (Epirrita autumnata, Lepidoptera:Geometridae) are not at a higher risk of parasitism: implications for the moth's lifehistory. Eur. J. Entom. 98:277-282.

The Heliconius Genome Consortium, Jiggins, C. D. 2012. Butterfly genome reveals promiscuous exchange of mimicry adaptations among species. Nature 487:94-98.

Umbers, K. D. L., and J. Mappes. 2015. Post-attack deimatic display in the mountain katydid (Acripeza reticulata). Anim. Behav. 100:68-73.

This article is protected by copyright. All rights reserved. 
Valkonen, J. K., O. Nokelainen, M. Niskanen, J. Kilpimaa, M. Bjöklund, and J. Mappes. 2012. Variation in predator species abundance can cause variable selection pressure on warning signaling prey. Ecol. Evol. 2:1971-1976.

Van Dyck, H., E. Matthysen, and C. Wiklund. 1998. Phenotypic variation in adult morphology and pupal colour within and among families of the speckled wood butterfly Pararge aegeria. Ecol. Entomol. 23:465-472.

Welch, J. J., and C. D. Jiggins. 2014. Standing and flowing: the complex origins of adaptive variation. Mol. Ecol. 23:3935-3937.

Weller, S., N. Jacobson, and W. Conner. 1999. The evolution of chemical defences and mating systems in tiger moths (Lepidoptera: Arctiidae). Biol. J. Linn. Soc. Lond. 68:557-578.

Williams, P. 2007. The distribution of bumblebee colour patterns worldwide: possible significance for thermoregulation, crypsis, and warning mimicry. Biol. J. Linn. Soc. Lond. 92: 97-118.

Windig, J. J. 1999. Trade-offs between melanisation, development time and adult size in Inachis io and Araschnia levana (Lepidoptera: Nymphalidae)? Heredity 82:57-68.

Zhang, J., V-P. Friman, J. Laakso and J. Mappes. 2012. Interactive effects between diet and genotypes of host and pathogen define the severity of infection. Ecology and Evolution. 2:2347-2356.

\section{Figure legends}

Figure 1. More melanic larvae with smaller warning signals (less efficient against predators, (Lindstedt et al. 2008)) develop into red females (efficiently defended against predators (Lindstedt et al. 2011)). Y-axis presents the mean phenotypic values (+- 1 SE) of the pedigree data for female 
coloration; 1 being the yellowest, 2-3 orange and 4-6 the reddest. X-axis presents categorical

signal values of larval coloration (the number of orange segments in larval body).

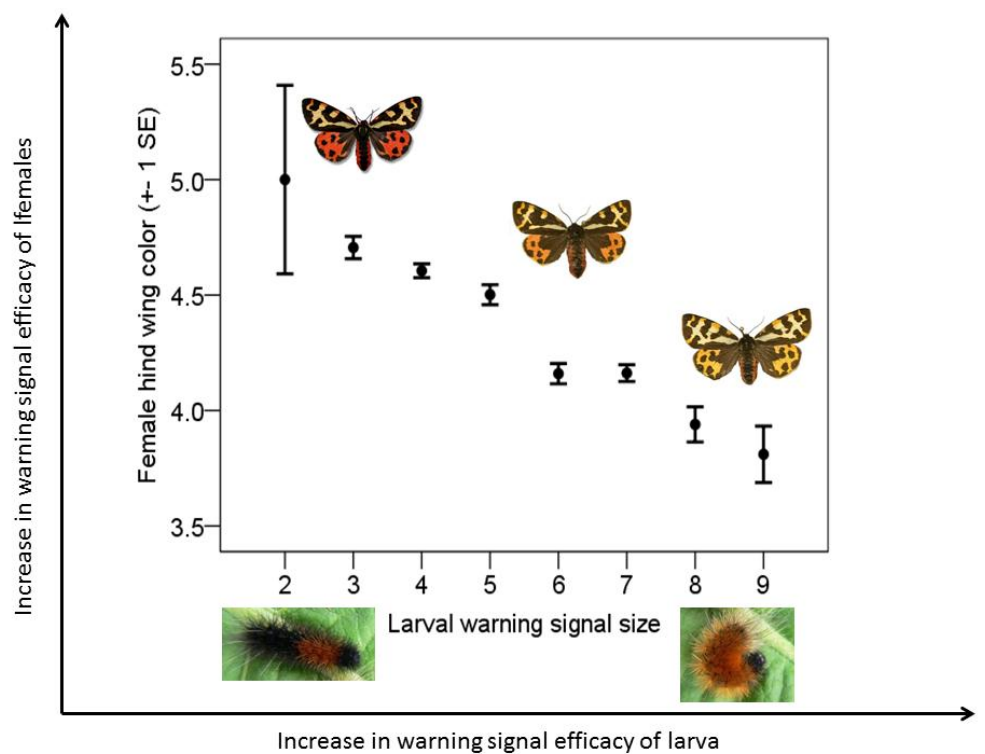

Table 1. Quantitative genetic parameters $(\mathrm{Va}=$ additive variance, $\mathrm{V} \mathrm{c}=\mathrm{common}$ family effect (including both genetic and non-genetic maternal variance), $V e=$ residual variance and $\mathrm{V} p=$ phenotypic variance) based on pedigree data for different signal and life history traits. Statistical significance of variance components was assessed with a Log Likelihood ratio test by dropping out alternately each random effect and comparing the Log Likelihood of the restricted model to full model.

\begin{tabular}{|c|c|c|c|c|c|c|c|c|c|c|c|c|c|c|c|}
\hline & $\mathrm{Va}$ & S.E. & h2 & S.E. & Vc & S.E. & c2 & S.E. & $\mathrm{Ve}$ & S.E. & $V p$ & S.E. & LogL & Va_P & Vc_P \\
\hline Larval signal size & 0.428 & 0.020 & 0.53 & 0.02 & & & & & 0.378 & 0.011 & 0.806 & 0.014 & -3166.570 & & \\
\hline \multirow[t]{3}{*}{$(1-12)$} & & & & & 1.673 & 0.078 & 0.76 & 0.01 & 0.521 & 0.007 & 2.194 & 0.078 & -3730.650 & & \\
\hline & 0.442 & 0.029 & 0.50 & 0.03 & 0.145 & 0.012 & 0.16 & 0.01 & 0.300 & 0.015 & 0.888 & 0.021 & -2833.880 & 0.000 & 0.000 \\
\hline & $\mathrm{Va}$ & & h2 & S.E. & Vc & S.E. & c2 & S.E. & $\mathrm{Ve}$ & S.E. & $V p$ & S.E. & Log $L$ & Va P & Vc_P \\
\hline \multirow{4}{*}{$\begin{array}{l}\text { Female coloration } \\
(1-6)\end{array}$} & 0.614 & 0.058 & 0.53 & 0.04 & & & & & 0.552 & 0.035 & 1.166 & 0.038 & -2005.930 & & \\
\hline & & & & & 0.334 & 0.027 & 0.29 & 0.02 & 0.824 & 0.020 & 1.158 & 0.031 & -2092.840 & & \\
\hline & 0.487 & 0.063 & 0.43 & 0.05 & 0.073 & 0.020 & 0.06 & 0.02 & 0.584 & 0.036 & 1.145 & 0.034 & -1996.200 & 0.000 & 0.000 \\
\hline & $\mathrm{Va}$ & & h2 & S.E. & Vc & S.E. & c2 & S.E. & Ve & S.E. & $V p$ & S.E. & LogL & Va_P & Vc_P \\
\hline \multirow[t]{4}{*}{ Pupa mass (mg) } & 726.290 & 54.413 & 0.29 & 0.03 & & & & & 1792.200 & 54.413 & 2518.400 & 52.534 & -2474.950 & & \\
\hline & & & & & 321.850 & 29.486 & 0.13 & 0.01 & 2100.300 & 36.179 & 2422.100 & 43.615 & -2480.930 & & \\
\hline & 334.290 & 71.091 & 0.14 & 0.03 & 162.840 & 28.811 & 0.07 & 0.01 & 1932.500 & 50.024 & 2429.600 & 46.572 & -2450.100 & 0.000 & 0.000 \\
\hline & $\mathrm{Va}$ & & h2 & S.E. & Vc & S.E. & c2 & S.E. & $\mathrm{Ve}$ & S.E. & $V p$ & S.E. & Log $\mathrm{L}$ & Va_P & Vc_P \\
\hline \multirow{4}{*}{$\begin{array}{l}\text { Development time } \\
(\log ) \times 100\end{array}$} & 2.456 & 0.138 & 0.94 & & & & & & 0.147 & 0.063 & 2.603 & 0.085 & -3271.810 & & \\
\hline & & & & & 1.903 & 0.146 & 0.62 & 0.02 & 1.146 & 0.025 & 3.049 & 0.147 & 760 & & \\
\hline & 1.432 & 0.254 & 0.47 & 0.07 & 1.185 & 0.133 & 0.39 & 0.04 & 0.439 & 0.125 & 3.056 & 0.153 & -3077.630 & 0.000 & 0.000 \\
\hline & $\mathrm{Va}$ & & h2 & S.E. & Vc & S.E. & c2 & S.E. & Ve & S.E. & $V p$ & S.E. & LogL & Va_P & Vc_P \\
\hline \multirow{4}{*}{$\begin{array}{l}\text { Maternal number } \\
\text { of eggs }\end{array}$} & 1169.900 & 487.980 & 0.17 & 0.07 & & & & & 5873.200 & 523.990 & 7043.100 & 435.580 & -2718.720 & & \\
\hline & & & & & 555.760 & 385.810 & 0.08 & 0.05 & 6630.900 & 520.360 & 7186.600 & 436.400 & -2728.520 & & \\
\hline & 1169.900 & 487.980 & 0.17 & 0.07 & 0.000 & 0.000 & 0.00 & 0.00 & 5873.200 & 523.990 & 7043.100 & 435.580 & -2718.720 & 0.000 & 1.000 \\
\hline & Va & & h2 & S.E. & Vc & S.E. & c2 & S.E. & $\mathrm{Ve}$ & S.E. & $V p$ & S.E. & LogL & Va_P & Vc_P \\
\hline \multirow{3}{*}{$\begin{array}{l}\text { Maternal offspring } \\
\text { number }\end{array}$} & 1384.800 & 601.600 & 0.14 & 0.06 & & & & & 8329.100 & 646.720 & 9713.800 & 509.610 & -3893.760 & & \\
\hline & & & & & 786.520 & 473.120 & 0.08 & 0.05 & 8995.600 & 618.510 & 9782.100 & 504.240 & -3900.720 & & \\
\hline & 1355.000 & 638.540 & 0.14 & 0.06 & 66.026 & 469.450 & 0.01 & 0.05 & 8293.100 & 687.650 & 9714.100 & 509.540 & -3893.750 & 0.000 & 0.888 \\
\hline
\end{tabular}

This article is protected by copyright. All rights reserved. 
Table 2. Genetic (rg) and environmental correlations ( $\mathrm{rc}$ ) were estimated from the pedigree data with a six trait model fitting all the life-history and/or signal traits simultaneously. Significance of the covariances were assessed by performing a Log Likelihood ratio test between a full model (LogL full model $=-2815.51$ ) and model in which covariance in question was constrained to zero. Correlations between the number of offspring and number of eggs did not converge.

\begin{tabular}{|c|c|c|c|c|c|c|c|c|c|c|c|c|c|c|c|c|c|c|c|c|c|c|c|c|c|}
\hline & \multicolumn{5}{|c|}{ Female coloration (1-6) } & \multicolumn{5}{|c|}{ Pupa mass (mg) } & \multicolumn{5}{|c|}{ Development time (log)x100 } & \multicolumn{5}{|c|}{ Maternal number of eggs } & \multicolumn{5}{|c|}{ Maternal number of offspring } \\
\hline & & & S.E. & LogL & $p$ & & & S.E. & LogL & $p$ & & & S.E. & LogL & $p$ & & & S.E. & LogL & $p$ & & & S.E. & LogL & $p$ \\
\hline \multirow[t]{4}{*}{ Signal size (1-12) } & $\mathrm{rg}$ & -0.2012 & 0.06 & -2821.7 & $<0.001$ & rg & 0.1096 & 0.0789 & -2817 & 0.126 & $\mathrm{rg}$ & 0.05 & 0.0705 & -2816 & 0.424 & rg & 0.4788 & 0.1966 & -2822 & $<0.001$ & $\mathrm{rg}$ & 0.2903 & 0.1208 & -2820 & 0.003 \\
\hline & ic & -0.0754 & 0.1 & -2815.8 & 0.462 & ic & 0.1677 & 0.0849 & -2817 & 0.048 & ic & 0.5632 & 0.0674 & -2836 & $<0.001$ & & & & & & & & & & \\
\hline & & & & & & & & & & & & & & & & & & & & & & & & & \\
\hline & & & & & & & & S.E. & LogL & $P$ & & & S.E. & LogL & $p$ & & & S.E. & LogL & $P$ & & & S.E. & LogL & $P$ \\
\hline \multirow[t]{4}{*}{ Female color (1-6) } & & & . & & & ig & -0.136 & 0.124 & .2816 & 0.327 & $\mathrm{rg}$ & -0.106 & 0.0993 & .2816 & 0.273 & rg & -0.117 & 0.2454 & -2816 & 0.655 & rg & 0.1309 & 0.1805 & -2816 & 0.498 \\
\hline & & & & & & ic & 0.2433 & 0.1687 & -2817 & 0.153 & ic & 0.082 & 0.1309 & -2816 & 0.527 & & & & & & & & & & \\
\hline & & & & & & & & & & & & & & & & & & & & & & & & & \\
\hline & & & & & & & & & & & & & S.E. & $\log \mathrm{L}$ & $P$ & & & S.E. & LogL & $P$ & & & S.E. & LogL & $P$ \\
\hline \multirow[t]{4}{*}{ Pupa mass (mg) } & & & . & & & & & . & & & rg & -0.224 & 0.1377 & -2817 & 0.106 & rg & 0.566 & 0.2803 & -2817 & 0.067 & rg & 0.4872 & 0.2243 & -2817 & 0.058 \\
\hline & & & & & & & & & & & ic & 0.0434 & 0.1116 & -2816 & 0.69 & & & & & & & & & & \\
\hline & & & & & & & & & & & & & & & & & & & & & & & & & \\
\hline & & & & & & & & & & & & & & & & & & S.E. & LogL & $P$ & & & S.E. & LogL & $P$ \\
\hline Development & & & - & & & & & . & & & & & . & & & rg & 0.5997 & 0.2906 & -2818 & 0.034 & $\mathrm{rg}$ & 0.3048 & 0.217 & -2816 & 0.164 \\
\hline \multirow[t]{3}{*}{ time (log)x100 } & & & & & & & & & & & & & & & & & & & & & & & & & \\
\hline & & & & & & & & & & & & & & & & & & & & & & & & & \\
\hline & & & & & & & & & & & & & & & & & & & & & & & S.E. & LogL & $p$ \\
\hline Maternal number & & & - & & & & & . & & & & & . & & & & & . & & & rg & 0.6718 & 0.2629 & * & * \\
\hline of eggs & & & & & & & & & & & & & & & & & & & & & & & & & \\
\hline & & & & & & & & & & & & & & & & & & & & & & & & & \\
\hline
\end{tabular}

This article is protected by copyright. All rights reserved. 